\section{Case Reports in Ophthalmology}

Case Rep Ophthalmol 2017;8:496-502

DOI: $10.1159 / 000480726$

Published online: October 26, 2017
(C) 2017 The Author(s)

Published by S. Karger AG, Basel www.karger.com/cop

This article is licensed under the Creative Commons Attribution-NonCommercial 4.0 International License (CC BY-NC) (http://www.karger.com/Services/OpenAccessLicense). Usage and distribution for commercial purposes requires written permission.

\title{
Diagnostic and Therapeutic Approach in a Case of Severe Post-Traumatic Hyphema with Subtotal Iridodialysis
}

\author{
Filippo Romanazzi Anna Morano Antonio Caccavale \\ Department of Ophthalmology, Abbiategrasso Hospital, Abbiategrasso, Italy
}

\section{Keywords}

Hyphema - Iridodialysis · Ultrasound - Ultrasound biomicroscopy · Traumatic cataract surgery · Iridoplasty

\begin{abstract}
Purpose: To report our diagnostic ultrasound-based approach and surgical strategy in a case of severe blunt trauma with complete hyphema, $270^{\circ}$ iris disinsertion, and traumatic subluxated cataract. Case Report: A 70-year-old male was referred to our hospital for a blunt trauma in his right eye. A complete examination revealed visual acuity consisting in light perception, a complete hyphema, and an intraocular pressure of $45 \mathrm{~mm} \mathrm{Hg}$ with moderate pain. Our diagnostic approached was ultrasound based with B-scan examination showing some vitreous hemorrhage and ultrasound biomicroscopy showing a large iris disinsertion of $270^{\circ}$ with the iris entirely dislocated in the inferior sector of the anterior chamber. The patient was hospitalized and a systemic and topical treatment was started to lower intraocular pressure. Our surgery consisted in a single-step approach with removal of traumatic cataract with scleral fixation of an intraocular lens and iridoplasty. Conclusion: In our patient, the single-step surgery, supported by anterior and posterior ultrasound imaging, achieved a satisfactory anatomical and functional outcome.

(C) 2017 The Author(s)

Published by S. Karger AG, Basel
\end{abstract}




\section{Case Reports in Ophthalmology}

\section{Introduction}

We present a case of an apparent minor trauma causing a severe damage of the eye consisting in complete hyphema, traumatic cataract with lens subluxation, and $270^{\circ}$ iridodialysis with the iris entirely dislocated in the inferior sector of the anterior chamber. Our diagnostic ultrasound-based approach and surgical strategy are described.

\section{Case Report}

A 70-year-old male was referred to our hospital for a blunt trauma in his right eye that occurred the day before. The patient told his 4-year-old nephew hit him with a rolled-up newspaper. Visual acuity was light perception, and intraocular pressure (IOP) was $45 \mathrm{~mm}$ $\mathrm{Hg}$ with moderate pain. Slit-lamp examination showed no corneal or conjunctival lesions. A complete hyphema with some undefined iris structures were visible in the inferior sector of the anterior chamber. It was not possible to see any other structures, the lens, or the posterior segment (Fig. 1). At light stimuli in the right eye, there was a pupillary response in the left eye.

Subsequently we performed, using our ultrasound platform (Aviso S- Quantel Medical), a B-scan examination (Fig. 2) showing some vitreous hemorrhage but no signs of retinal detachment. We performed also an ultrasound biomicroscopy (UBM) with a 50-MHz ultrasound probe revealing a large iridodialysis with the iris entirely dislocated in the inferior sector of the anterior chamber (Fig. 3). The patient was hospitalized and a systemic (mannitol i.v. and oral acetazolamide) and topical (timolol 0.05\%) ocular hypotensive therapy was started. Topical therapy consisted also of cortisone and heparin drops. Therapy was able to control the ocular pressure and the pain and, after 5 days, the hyphema disappeared revealing a $270^{\circ}$ iridodialysis (Fig. 4) with the iris root attached only in the inferior-temporal sector and a traumatic cataract. It was possible to see the fundus with no evidence of serious retinal damages and mild vitreous hemorrhage. Preoperatively, we obtained an ultrasound biometry for intraocular lens power selection, because the position of the iris did not allow measurements with optical devices.

At this time, the surgical procedure consisted in a phacoemulsification of traumatic subluxated cataract with removal of the residual capsular bag and a scleral fixation of intraocular lens followed by iridoplasty (Fig. 5).

In particular, we started with a capsule-conjunctival peritomy from 9 to 6, 2.2-mm corneal incision at 12 o'clock, and two paracenteses at 3 and 9 . Iris was entirely captured by two prolene hooks in the inferior-temporal sector. During phacoemulsification, due to the large subluxation of the lens, we were able to remove the nucleus in two pieces but residual capsular bag and cortical remnants were removed by anterior 23-G vitrectomy together with the prolapsed vitreous.

After creation of two scleral pockets at 3 and 9, we proceeded with scleral fixation of an intraocular lens. Then we removed the iris hooks and started a complexed iridoplasty using a 10-0 prolene double-armed straight needle and a $23-G$ vitreous forceps to fix the iris root with three mattress stitches at 11,1, and 3 o'clock at $1.5 \mathrm{~mm}$ from the limbus. In this way, we obtained a circular pupil, even though large (Fig. 6). We concluded the surgical intervention with a careful removal of viscoelastic sutures of the scleral, conjunctival, and corneal wounds. In the postoperative period, we controlled a moderate increase of IOP (29 $\mathrm{mm} \mathrm{Hg}$ ) with oral acetazolamide and topical drugs, other than a moderate flare with chlorampheni- 
Case Reports in
Ophthalmology

Case Rep Ophthalmol 2017;8:496-502

DOI: $10.1159 / 000480726$

C 2017 The Author(s). Published by S. Karger AG, Basel www.karger.com/cop

Romanazzi et al.: Diagnostic and Therapeutic Approach in a Case of Severe PostTraumatic Hyphema with Subtotal Iridodialysis

col-betamethasone drops. After 1 week, with IOP of $18 \mathrm{~mm} \mathrm{Hg}$, we stopped oral acetazolamide and continued with dorzolamide-timolol fixed combination drops twice daily. After 2 weeks, with IOP of $16 \mathrm{~mm} \mathrm{Hg}$, we stopped dorzolamide-timolol fixed combination and followed with only timolol drops twice daily. After another 2 weeks, we stopped timolol and chloramphenicol-betamethasone drops and the patient had only therapy with topical nonsteroidal anti-inflammatory drops 2 times a day for 1 month. At postoperative 3 months, there was no evidence of residual flare and IOP was normal.

During follow-up, vitreous hemorrhage spontaneously partially resolved within 1 month and, completely, at 2 months after surgery and it did not need any other surgical procedures.

\section{Discussion}

We treated a case of a severe disruption of the anterior segment caused by an apparently common minor trauma [1]. The patient was not affected by systematic or ocular comorbidities that could promote bleeding. We suppose that the particular distribution of the forces on the anterior segment provoked such a large iridodialysis.

A careful ultrasound examination of the eye, by B-scan of the posterior segment and UBM, is mandatory in such cases for a better diagnostic and surgical plane [2-4]. A delayed surgery, controlling in the meantime spikes of IOP, can be better than an immediate one and less dangerous [5].

To control IOP, we chose mannitol i.v. to lower it in a short time and then oral acetazolamide and topical drops to maintain the IOP under $20 \mathrm{~mm} \mathrm{Hg}$. We added cortisone drops to control the inflammation. We added heparin drops too for their anti-inflammatory properties (such as inhibition of activated granulocytes and inhibition of release of free radicals and other chemical mediators of inflammations), and their capacity of lysis of proteins in the anterior chamber, due in this case to the large iridodialysis. Heparin inhibits also fibrin formation $[6,7]$.

In this case, we chose a complex iridoplasty [8], despite the fact that the iris was attached only by one-fourth but in absence of evident stromal necrosis, instead of a total iridectomy with an artificial diaphragm. This approach permitted reducing the risk of intraoperative bleeding, restoring a useful functional and esthetic appearance of the eye.

In the postoperative period, we had to control an increase in IOP; we think that was due to some residual viscoelastic solution used during surgical procedures, which was spontaneously reabsorbed during postoperative weeks 4-6.

Subtotal iridodialysis, more often occurring during surgical procedures or perforating trauma $[9,10]$, is rare in blunt trauma. This case in our opinion is demonstrative insofar that, even in minor trauma, it can occur and ultrasound examination is mandatory to plan the correct surgical strategy. In this case, UBM was able to accurately highlight the situation of the anterior segment before hyphema disappeared and B-scan examination, demonstrating a mild vitreous hemorrhage, convinced us to delay a posterior vitrectomy, which later was not necessary. 


\section{Conclusion}

We obtained a good result with a single-step surgery. Best corrected visual acuity was $7 / 10$ at postoperative 4 months. The patient did not experience a significant photophobia and, in the future eventuality of this symptom, it will be possible to obtain a better and narrow pupil morphology by means of pupilloplasty or with an artificial iris diaphragm.

\section{Statement of Ethics}

The authors have no ethical conflict to disclosure. Written informed consent was provided by the patient to have the case details and accompanying images published.

\section{Disclosure Statement}

The authors report no conflicts of interest in this work. No funding was received for this work.

\section{References}

1 Ashaye AO: Traumatic hyphaema: a report of 472 consecutive cases. BMC Ophthalmol 2008;8:24.

-2 Dessì G, Lahuerta EF, Puce FG, Mendoza LH, Stefanini T, Rosenberg I, Del Prato A, Perinetti M, Villa A: Role of B-scan ocular ultrasound as an adjuvant for the clinical assessment of eyeball diseases: a pictorial essay. J Ultrasound 2014;18:265-277.

-3 Berinstein DM, Gentile RC, Sidoti PA, Stegman Z, Tello C, Liebmann JM, Ritch R: Ultrasound biomicroscopy in anterior ocular trauma. Ophthalmic Surg Lasers 1997;28:201-207

-4 Genovesi-Ebert F, Rizzo S, Chiellini S, Romani A, Gabbriellini G, Sartini MS, Nardi M: Ultrasound biomicroscopy in the assessment of penetrating or blunt anterior-chamber trauma. Ophthalmologica 1998;212(suppl 1):6-7.

5 Bansal S, Gunasekeran DV, Ang B, Lee J, Khandelwal R, Sullivan P, Agrawal R: Controversies in the pathophysiology and management of hyphema. Surv Ophthalmol 2016;61:297-308.

6 Rumelt S, Stolovich C, Segal ZI, Rehany U: Intraoperative enoxaparin minimizes inflammatory reaction after pediatric cataract surgery. Am J Ophthalmol 2006;141:433-437.

7 Ozkurt YB, Taskiran A, Erdogan N, Kandemir B, Dogan OK: Effect of heparin in the intraocular irrigating solution on postoperative inflammation in the pediatric cataract surgery. Clin Ophthalmol 2009;3:363365 .

-8 Okamoto Y, Yamada S, Akimoto M: Suturing repair of subtotal iridodialysis. Int Ophthalmol 2017, DOI: 10.1007/s10792-017-0465-y.

-9 Walker NJ, Foster A, Apel AJ: Traumatic expulsive iridodialysis after small-incision sutureless cataract surgery. J Cataract Refract Surg 2004;30:2223-2224.

10 Oshika T, Amano S, Kato S: Severe iridodialysis from phacoemulsification tip suction. J Cataract Refract Surg 1999;25:873-875. 
Case Reports in
Ophthalmology

Case Rep Ophthalmol 2017;8:496-502 DOI: $10.1159 / 000480726$

(C) 2017 The Author(s). Published by S. Karger AG, Basel www.karger.com/cop

Romanazzi et al.: Diagnostic and Therapeutic Approach in a Case of Severe PostTraumatic Hyphema with Subtotal Iridodialysis

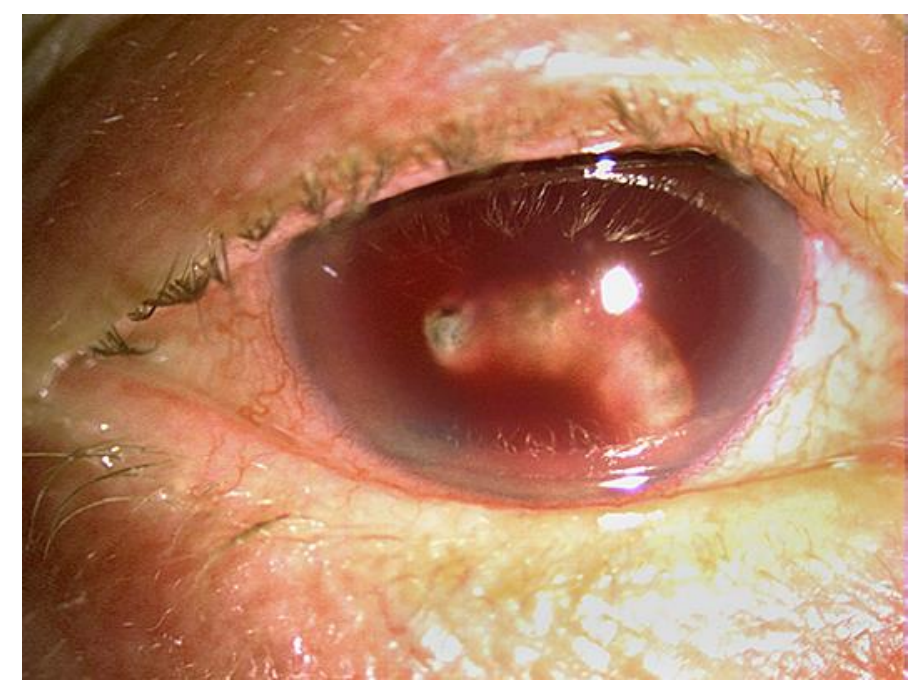

Fig. 1. Appearance of the anterior chamber with complete hyphema.

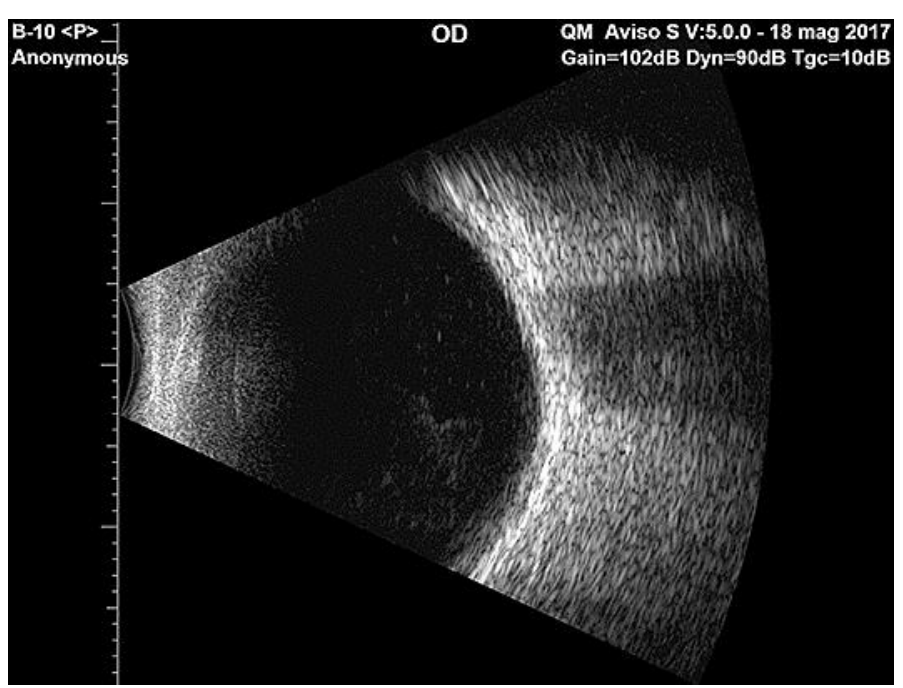

Fig. 2. B-scan examination showing some vitreous hemorrhage. 


\section{Case Reports in Ophthalmology}

\begin{tabular}{l|l}
\hline Case Rep Ophthalmol 2017;8:496-502 \\
\hline DOI: $10.1159 / 000480726$ & $\begin{array}{l}\text { ○ } 2017 \text { The Author(s). Published by S. Karger AG, Basel } \\
\text { www.karger.com/cop }\end{array}$ \\
\hline
\end{tabular}

Romanazzi et al.: Diagnostic and Therapeutic Approach in a Case of Severe PostTraumatic Hyphema with Subtotal Iridodialysis

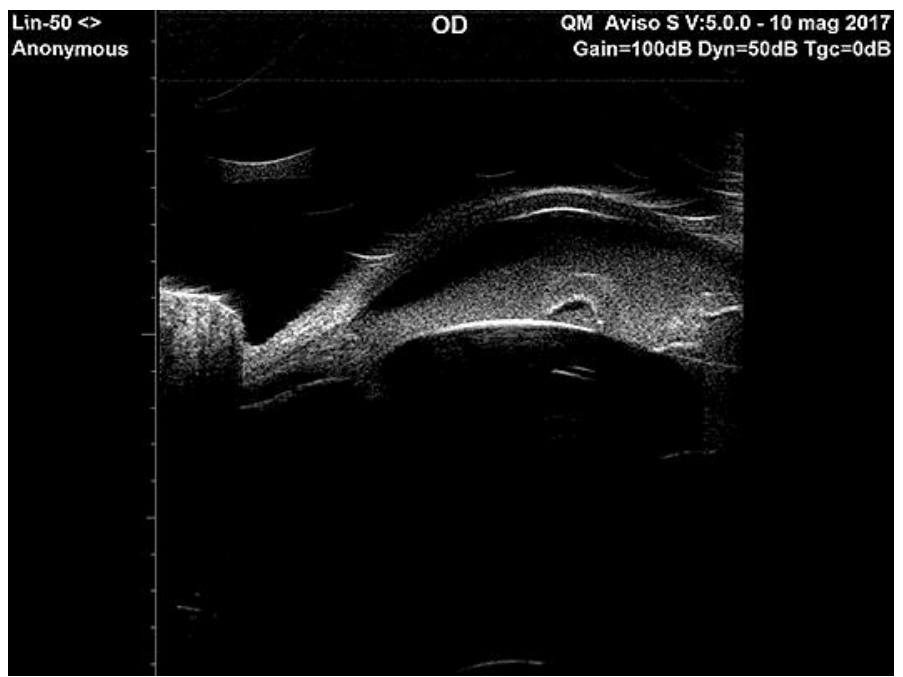

Fig. 3. Ultrasound biomicroscopy showing large iris disinsertion and hyphema.

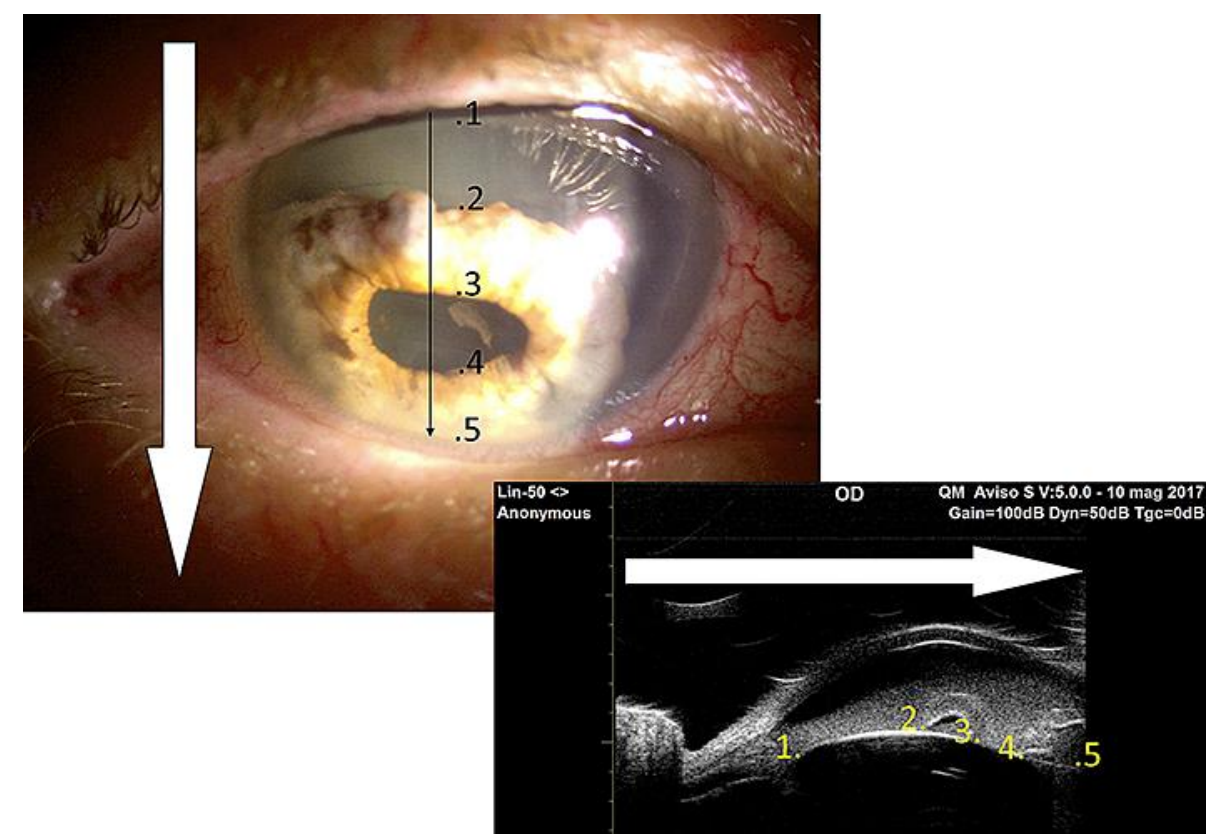

Fig. 4. Examination at slit lamp after resolution of hyphema and correspondence with ultrasound biomicroscopy. 


\section{Case Reports in Ophthalmology}
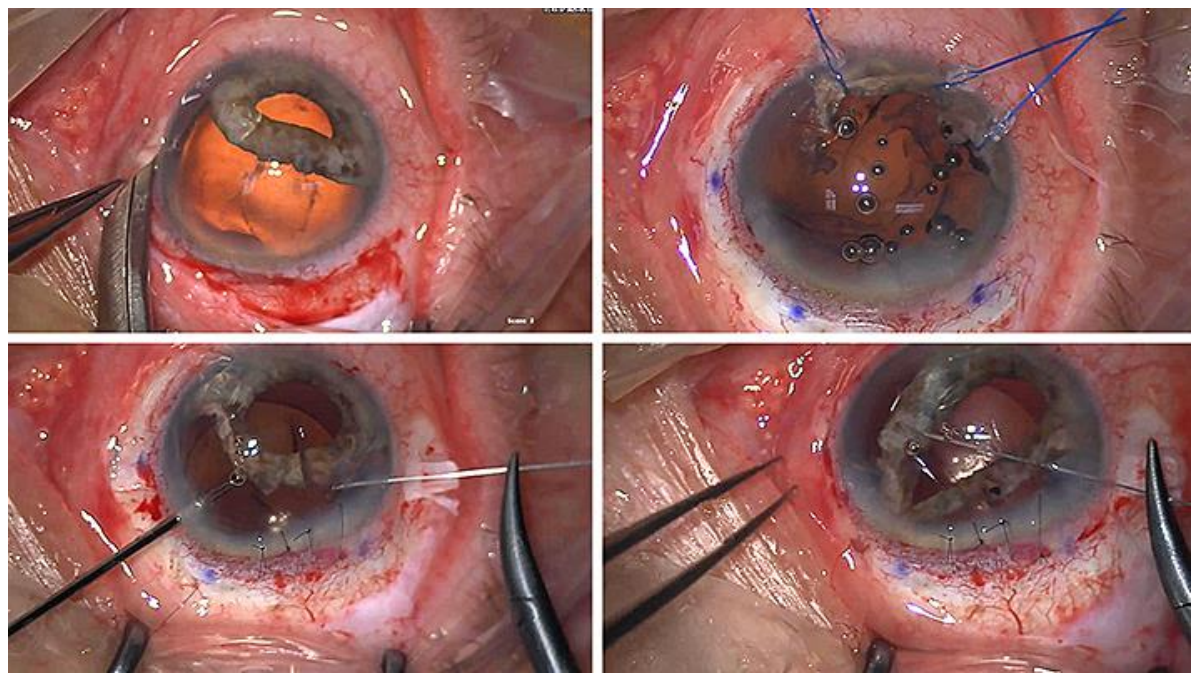

Fig. 5. Some surgical phases. Presentation with $270^{\circ}$ iridodialysis and subluxated cataract (left, top). Apposition of iris hooks and cataract surgery (right, top). Scleral fixation of an intraocular lens and beginning of iridoplasty (left, bottom). Phases of iridoplasty (right, bottom).

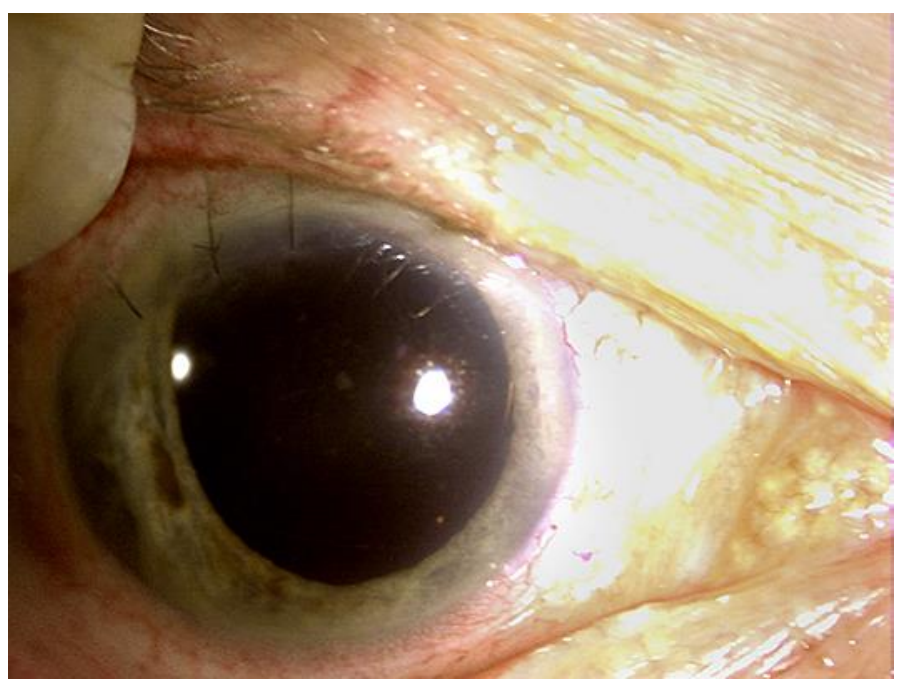

Fig. 6. Anterior segment in the postoperative period at 3 weeks. 